\title{
Yeon-Koo Che*
}

\section{Eliciting Multi-Dimensional Care through Liability and Regulation}

DOI 10.1515/ajle-2016-0029

Abstract: This paper examines the incentive performance of liability and regulation when a potential injurer can take two types of preventative care, one of which is observed and one of which is not. The problem is studied in a general asymmetric information model, where settlement behavior is endogenous and which incorporates an uncertain legal standard. Contrary to existing literature, we find (1) a shift to a negligence rule may have a perverse effect on unobserved care; (2) uncertainty in legal standards may be socially beneficial as it provides a relatively good incentive for unobserved care; (3) a regulation may not be effective if preventative care efforts are substitutes but is effective if they are complements; (4) an increase in settlement rate may or may not increase the level of care, depending on the cause of the increase; (5) a "decoupling" arrangement with a feature that the defendant pays more than the plaintiff recovers, reduces legal costs and is therefore socially beneficial.

Keywords: liability; preventative care; regulation.

\section{Introduction}

This paper studies incentives for care taking under alternative liability rules, when relevant care consists of more than one type of activity. Often, a potential injurer, in a product or accident liability context, can engage in more than one type of effort in reducing the probability of accident. Examples are numerous: a nuclear power plant can purchase a safety facility and/or engage in a longer period of preventative maintenance to avoid safety problems; a chemical company can reduce the level of pollution by installing an anti-polluting facility and/or by changing a manufacturing process; a pharmaceutical company can put on a warning label and/or engage in a product $R \& D$ to reduce the potential side-effect of a medicine. The problem of injurer (e.g. driver) deciding both the amount of risky activity (e.g. the amount of driving) and the level of care (e.g. speed) during

*Corresponding author: Yeon-Koo Che, Department of Economics, Columbia University, New York, NY, USA, e-mail: yc2271@columbia.edu 
the risky activity is also a special example of the two activity problem. The model is this paper will consider two types of injurer's efforts, one of which is publicly observable (e.g. the purchase of safety facility or putting on a warning label) and one of which is not (e.g. maintenance activity or design change).

How does the modern tort system deal with such incentive problems? How can it be changed to improve the incentives for care? What are the supplementary roles of (safety) regulations in the presence of liability litigation? These question have been studied in many different ways in a single effort context. But the answers and insights gained from these studies are confined to the one-dimensional care restriction. How restrictive the assumption is will be an empirical as well as a theoretical question. It is the objective of this essay to demonstrate that at least theoretically the answer is yes.

In addition to the two-effort assumption, the model tries to be more realistic in describing the litigation process. First, the mode, by adopting an asymmetric information model similar to Bebchuk (1984) and Che and Yi (1990), endogenizes settlement behavior as determined though pre-trial bargaining. The benefit of this feature is immediate: we can ask, in a single, integrated fashion, a fundamental question of tort law reform - how can we minimize the occurrence of accident with the least legal cost ${ }^{1}$ Secondly, in representing the negligence rule, I introduce uncertainty in a court's applying the legal standard of "due care." This is to capture the ex-ante unpredictability of a court decision in which the jury is delegated with the responsibility of interpreting whether or not an injurer has failed to take "due care" in the conduct leading to the accident. ${ }^{2}$

With this general two-effort care taking/litigation, model, several pieces of common wisdom established in the one-effort model are no longer valid. Consider the following reasonable statements.

(i) With judgment-proofness (limited asset of the defendant), a negligence rule provides a sharper and better incentive for care than the strict liability. (Shavell 1986)

(ii) Uncertainty in legal standards are socially costly, creating over-compliance/ extra precaution on the part of the potential injurer. (Calfee and Craswell 1984)

1 This paper is not the first in integrating the problem of care taking in a framework where the settlement is endogenously determined. P'ng (1987) has the similar feature in a signaling framework. Polinsky and Rubinfeld (1988) does not endogenize the settlement but considers the incentive for care and the incentive for suit in an integrated fashion.

2 Calfee and Craswell (1984) investigates the implications of uncertain legal standards. The objective of this added realism in this paper is not to reproduce their result but to highlight a different result obtained in the two-dimensional effort context. 
(iii) Changing regulatory standard can directly improve the incentives for care where/if the liability provides insufficient incentives. (Shavell 1984) ${ }^{3}$

(iv) Increased possibility of out-of-court settlement reduces the incentive for care as it implies decreased liability costs. (Polinsky and Rubinfeld 1988)

These statements are challenged in this model. We find:

(i') Compared to strict liability, the negligence rule may have a perverse effect on incentives: With substitutary effort interaction, ${ }^{4}$ the negligence rule, which sharpens only the incentive for observed care, deteriorates the incentive for unobserved care. This is due to two effects: (1) the negligence rule provides an extra layer of immunization of a potential injurer, resulting in the reduction of the injurer's expected liability (relative to strict liability); (2) an added incentive from the negligence rule on observed care diverts the attention of the potential injurer away from unobserved care. The latter effect was first introduced in a principal-agent framework by Holmstrom and Milgrom (1991). The result suggests that for example in the example of nuclear power plants too many safety facilities are installed and too little maintenance effort is exerted; in the example of the pharmaceutical company, too many warning labels are put on while too little effort is exerted in the R\&D process to enhance the safety properties of the product.

(ii') Uncertain negligence standards may be socially beneficial: Under the unpredictable negligence standard, even the one who tool a significantly high level of care will face some chance of being held liable. This leaves a comparatively better incentive for unobserved care than the certain negligence rule, under which a fully immunized injurer has no incentive for the unobserved care. One practical implication from this observation will be that the current approach which delegates to the jury the burden of interpreting the standard of "due care" is not entirely misguided.

(iii') If the efforts are substitutes, a regulatory standard with any impact at all deteriorates the incentive for one type of care; while, if the efforts are complements, a regulatory action could improve both type of care: Intuition for this result is similar to $\left(i^{\prime}\right)$ : a regulatory action can sharpen the incentive for

3 While Shavell (1984) considers a more sophisticated version with a continuum of injurers posing different levels of harm, the stated result would be trivially implied when the distribution of injurers collapses to a single type.

4 This refers to a situation where increasing the level of one effort increases the marginal cost of the other effort. This would be a likely outcome if there is some rigid budget or time constraint so that an added emphasis on one activity diverts the attention away from the other activity, resulting in the decreased efficiency for the latter. 
one type of care only at the expense of blunting the incentive for the other when the efforts are substitutes; while a positive reinforcement would be induced between the two efforts if they were complements.

$\left(\right.$ iv $\left.^{\prime}\right)$ With out-of-court settlement endogenously determined, the settlement rate loses its explanatory power for its effect on the level of care: An increase in the settlement rate may decrease or increase the defendant's liability, depending on the factors responsible for the increase in the settlement. For example, the defendant's litigation costs will increase the settlement rate but they will also increase her liability costs, increasing her incentive for care; while the opposite effect will occur if the plaintiff's litigation costs decrease.

Besides these, we establish the following result.

$\left(\mathrm{v}^{\prime}\right)$ A damage multiplier, which can be used to improve the incentive performance of the strict liability (Polinsky and Rubinfeld 1988), may perform better with the use of "decoupling”: Decoupling makes it possible to separate the settlement incentive form the adjustment of the liability costs. Therefore, with an appropriate use of decoupling, one could adjust liability costs to a socially desirable level without worrying about their effect on the settlement rate.

This paper is organized as follows. Section 2 describes the model. In Section 3, an asymmetric information litigation model similar to Bebchuk (1984) and Che and Yi (1990) is developed with an added feature of the defendant's judgmentproofness. All the results of the analysis of the section will be summarized by a simple, reduced-form liability function, which is to be used as primitive in the later sections concerning the initial stage of care taking. A reader not interested in the litigation process itself may skip the section and go directly to Section 4, which presents the main analysis of the incentives under alternative liability rules. Section 5 will consider the implications on safety regulation. Concluding remarks will follow thereafter.

\section{The Model}

We consider a simple two-stage model of care-taking and litigation where a stylized model of litigation, similar to Bebchuk (1984) and Che and Yi (1990) is imbedded as a second state game. The model involves three parties: an injurer (or a defendant), a victim (or a plaintiff), and the court. Later we introduce a regulatory agency as the fourth party. The following notations are used throughout the paper: 
$e_{1}=$ level of observed care;

$e_{2}=$ level of unobserved care;

$e_{1}=$ level of negligence standard, realized at trial, and distributed over

$\left[e_{1}^{-}, e_{1}^{+}\right]$according to a continuously differentiable distribution function $G$ with density $g$

$q\left(e_{1}, e_{2}\right)=$ probability that an accident occurs when $e_{1}$ and $e_{2}$ are taken;

$\psi\left(e_{1}, e_{2}\right)=$ disutility from efforts, $e_{1}, e_{2}$;

$W=$ damage realized as the victim's private information, and distributed over

$[0, \bar{W}]$ according to a twice differentiable distribution function $F$ with an density $f$;

$B=$ liability limit, equal to the asset held by the defendant;

$S=$ the level of settlement offer by defendant;

$c=$ litigation costs of trial, incurred by the plaintiff;

$d=$ litigation costs of trail, incurred by the defendant;

$p=$ probability that the plaintiff wins the trail.

Timing of the game, depicted in Figure 1. is as follows. First, the potential injurer takes care with levels, $e_{1}$ and $e_{2}$. Second, an accident occurs with probability, $q\left(e_{1}, e_{2}\right)$ and a level of damage, $W$ is realized to the victim, as private information. Third, litigation begins with a pre-trial bargaining, in which the defendant makes a take-it-or-leave-it settlement offer, $S,{ }^{5}$ to which the plaintiff responds by accepting or rejecting the offer. Finally, if the offer is rejected, a trial takes place. In the trail, the court reveals and awards the actual damage $W$ to the plaintiff, if the jury finds the defendant liable (which occurs with probability $p$ ).

The next section will analyze the litigation problem given fixed values of parameters $(B, p, c, d)$. For convenience, it is sufficient at this moment to say that the result of analyzing the litigation problem will be succinctly summarized by a reduced form, (expected) liability function $L(B, p)^{6}$ that the defendant will face at the end of the first stage. Expected social loss from the accident is the sum of the defendant's liability, $L(B, p)$ and the victim's loss, $E W-U(B, p)=E W-L(B, p)+1$,

5 Two comments are warranted. First, in this asymmetric information problem, the decision by the plaintiff to bring a suit is trivial: with accepting the settlement available as an option, the plaintiff does not lose anything by suing. In other words, in this model the suit does not commit the plaintiff to the trial. To see the opposite phenomenon, see Polinsky and Rubinfeld (1988). Second, one might think the model overly simplifies the subtlety of the pre-trial bargaining. However, any more sophisticated bargaining model will produce equilibria, converging to the one in this model, as a defendant's bargaining power grows to its monopoly - not an unreasonable description of the most product liability cases in which a big entity like a firm is pitted against consumers.

6 The function also depends on $(c, d)$. For simplicity, the two parameters will be suppressed for most of the analysis. 


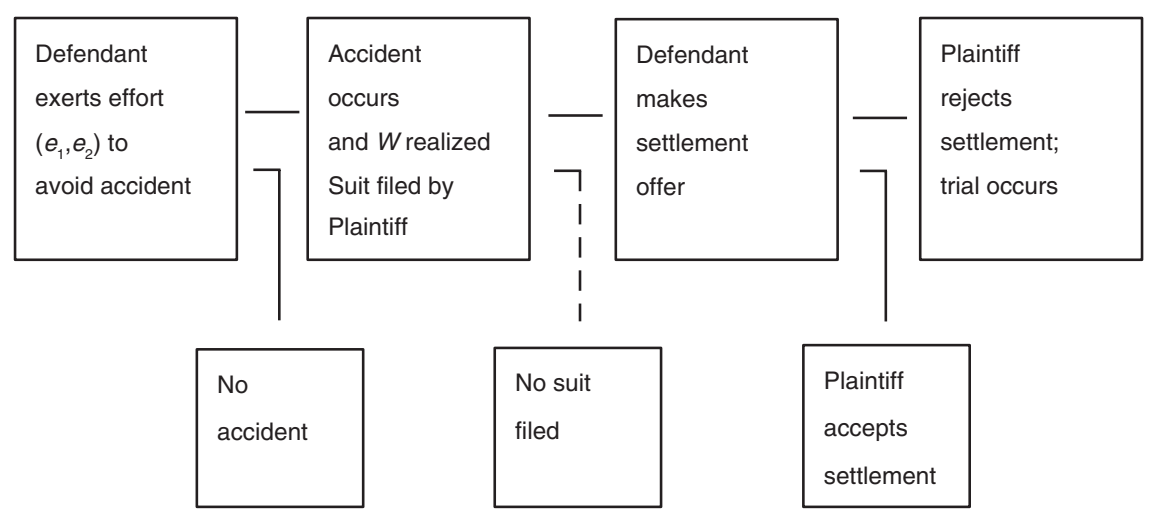

Figure 1: Timing of the Game.

and thus equals $E W+1,{ }^{7}$ where $U(B, p)$ and 1 denote expected recovery of the plaintiff and expected legal costs, respectively. From a social point of view, the first best policy will be to set $l=0$ and choose $e_{1}$ and $e_{2}$ to

$$
\text { Minimize } C^{*}\left(e_{1}, e_{2}\right) \equiv q\left(e_{1}, e_{2}\right) E W+\psi\left(e_{1}, e_{2}\right) \text {. }
$$

For the moment, assume the problem is well defined and that it has a unique solution $\left(e_{1}, e_{2}\right)^{*}$. $^{8}$

The injurer's first period problem of care taking depends on the liability rule chosen by the court. In the model, liability rules are represented by how the plaintiff's winning probability, $p$ [which appears in $L(B, p)$ ] is determined in this court. Under strict liability, the court awards (compensatory) damage $W$ subject to a limited assets, $B$ if and only if the damage is verified. ${ }^{9}$ The probability that the damage is verified is $p_{s}=p_{v}$. Under the negligence rule, compensatory damage is awarded when the court verifies (with prob. $p_{v}$ ) the level $W$ and finds the defendant negligent. With an uncertain legal standard in our model, the latter

7 Here, we abstract from distributional issues. Therefore, holding the accident rate fixed, an arrangement which minimizes the legal costs is deemed the best, no matter what the victim recovers.

8 Later on, in Section 4, a sufficient condition will be given to guarantee this.

9 In actuality, torts apply a basic standard to determine whether or not a defendant is responsible for an accident. In case of product liability, the standard is that a product is defective and the defect is unreasonably dangerous to the consumer. In principle the standards applied under the strict liability may affect the incentive for care. However, a modern trend of torts emphasizes the compensatory insurance grounds, justifying the representation in the model. For details of torts and their reform, see Priest (1987a,b, 1991). 
event occurs when the level of observed care $e_{1}$ falls short of the negligence standard, $e_{1}$, which is realized at the trial by a distribution function, $G$; i.e. $e_{1}<e_{1}$. The probability of this event is $1-G\left(e_{1}\right)$. Therefore, under the negligence rule, $p_{n}\left(e_{1}\right)=p_{v}\left(1-G\left(e_{1}\right)\right)$. We initially set $e_{1}^{-}=0$ and $e_{1}^{+}=\infty$. Notice $p_{n}^{\prime}\left(e_{1}\right)=p_{v} g\left(e_{1}\right)<0$; i.e. the potential injurer can reduce the chance of being found negligent by increasing the level of the observed care $e_{1}$. It will turn out that this generates an extra incentive for $e_{1}$ under the negligence rule. Finally, for the sake of completeness and comparison with the literature, we consider the case with a "certain" negligence standard, where $G$ is a step function:

$$
G\left(e_{1}\right) \begin{cases}0, & \text { if } e_{1}<e_{1}^{*} \\ 1, & \text { if } e_{1} \geq \underline{e_{1}^{*}}\end{cases}
$$

for some predetermined standard $e_{1}^{*}$. We call this certain negligence rule. With this characterization of the liability rules, the first period problem of the potential injurer can be described as:

$$
\min _{e_{1}, e_{2}} C^{i}\left(e_{1}, e_{2}\right) \equiv q\left(e_{1}, e_{2}\right) L\left(B, p_{i}\right)+\psi\left(e_{1}, e_{2}\right) .
$$

where $i=S, N, C N$, denote alternative liability rules.

\section{Second Period Litigation}

In this section, we analyze the second period litigation game. While solving the litigation problem will serve as a preliminary step of deriving and characterizing the liability function, $L(B, p)$ - a necessary primitive of the analysis in the next sections, it is also interesting in its own right. Among others, it reveals the settlement behavior of the parties given a number of parameters, some of which are exogenously given and some of which are determined by the actions taken through the previous stage. We adopt an asymmetric litigation model similar to Bebchuk (1984) and Che and Yi (1990). The only difference in this model is that a feasible level of judgment is limited by the injurer's asset, $B$. The solution concept we use is that of Bayesian Perfect Equilibria. As usual, we work backwards.

Consider the last move by victim. Having received a settlement offer $S$, the victim (plaintiff) is better off accepting any positive offer greater than his expected gain from trial. The expected gain from trial for the victim with damage $W$ is given by the probability of winning, $p$, times the feasible damage award, $\min \{B, W\}$, minus the litigation costs, $c$. In summary, the optimal decision rule of the plaintiff with damage $W$ is: 


$$
[P] \text { “Accept if } S \geq \max \{p \min \{B, W\}-c, 0\} \text { ”. }
$$

Now consider the settlement offer made by the defendant. Letting $w=\frac{S+c}{p}$, the defendant's problem is essentially the same as picking $w\left(\geq \frac{c}{p}\right)$, knowing that the offer will be responded by $[P]$. There are two different possibilities: the defendant either picks $w \geq B$ and induces a full settlement or picks $w<B$ and risks going to court with probability $1-F(w)$, in which case he incurs litigation costs $d$. Thus, the optimal decision by the defendant is summarized as:

$$
[D] L(B, p) \equiv \min L(w ; B, p)=\left\{\begin{array}{cc}
w p-c, & \text { if } w \geq B \\
L(w ; B, p), & \text { if } w<B
\end{array}\right.
$$

where

$$
\bar{L}(w ; B, p)=(w p-c) F(w)+d[1-F(w)]+p \int_{w}^{\bar{W}} \min \{B, \tilde{W}\} d F(\tilde{W}) .
$$

We make the following assumptions.

[A1]: $h^{\prime}>0$, where $h=\frac{F(w)}{f(w)}$

[A2]: $\min _{w \in[c / p, \bar{w}]} L(w ; B, p)$ has an interior solution.

With [A1] and [A2], the necessary and sufficient condition for $\min _{w \in[c / p, \bar{w}]}$ is $h\left(w^{*}\right)=\frac{c+d}{p}$. [see proposition 0 of Che and Yi (1990).] The following proposition characterizes the solution of $[D]$.

Proposition 1: If [A1] and [A2] hold, then [D] has the unique solution, for which

(i) there exists $\hat{B} \in\left(w^{*}, \bar{W}\right)$ such that for $B \leq \hat{B}$ a full settlement occurs with $S^{*}=\max \{B p-c, 0\} ;$ and for $B>\hat{B}$ a partial settlement occurs with $S^{*}=w^{*} p-c$ where the plaintiff with damage less than $w^{*}$ settles;

(ii) both $\hat{B}$ and $w^{*}$ are increasing in $c$ and $d$ but decreasing in $p$.

The result can be easily explained by inspecting Figure 2A. If the damage limit, characterized by the defendant's asset level, $B$, is not sufficiently larger than an otherwise interior solution, $w^{*}$, it pays the defendant to offer the limit and induce a full settlement rather than to offer a not much smaller amount, $w^{*}$ and risk a trial (and litigation costs, $d$ ) with probability $1-F\left(w^{*}\right)$. This feature is reflected in the discontinuous drop in an equilibrium settlement offer in Figure 2A. 
A

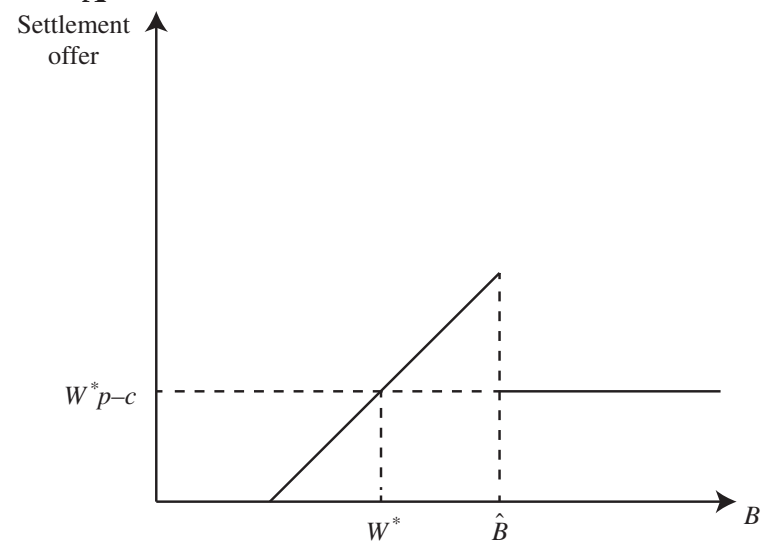

B

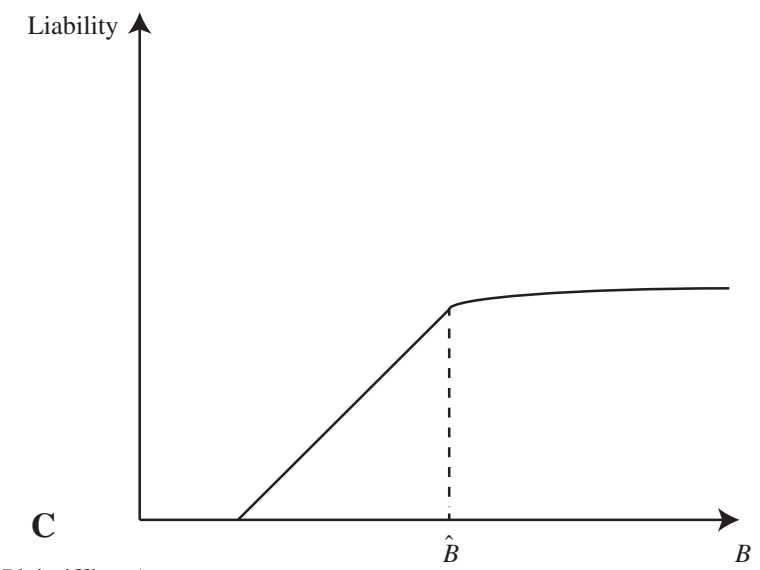

Plaintiff's expected recovery

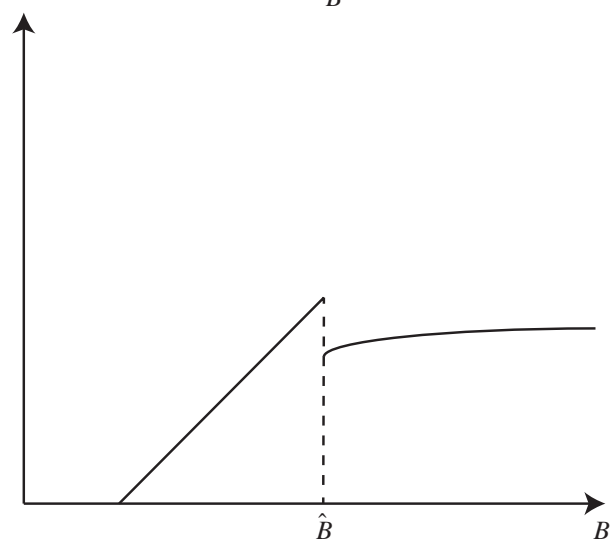

Figure 2: (A) A Change in the Settlement Offer with Respect to $B$. (B) A Change in the Liability with Respect to $B$. (C) A Change in the Plaintiff's Expected Recovery with Respect to $B$. 
As for (ii) of the proposition, the usual explanation applies. An increase in the litigation costs of either party will pressure the affected party to settle more easily; while a decrease in the plaintiff's winning probability will increase the plaintiff's willingness to settle much more than it will decrease the defendant's willingness to avoid trial, resulting in the increase of the settlement rate. The increase in the settlement takes two different forms in our judgment proof problem: a full-settlement zone expands and the settlement rate increases in a partial settlement zone.

An important side product of the proposition is the characterization of the function, $L(B, p)$ [or $L(B, p, c, d]$ in an unsuppressed version), called the expected liability of the potential injurer. Observe

$$
L(B, p)=\left\{\begin{array}{cc}
\max (B p-c, 0), & \text { if } B \leq \hat{B} ; \\
\bar{L}\left(w^{*} ; B, p\right), & \text { if } B \geq \hat{B},
\end{array}\right.
$$

which is graphically presented in Figure 2B.

Similarly, the plaintiff's expected recovery can be obtained by subtracting the expected legal costs from the liability costs of the defendant.

$$
U(B, p)=\left\{\begin{array}{c}
L(B, p), \quad \text { if } B \leq \hat{B} \\
L(B, p)-\left[1-F\left(w^{*}\right)\right](c+d), \quad \text { if } B \geq \hat{B},
\end{array}\right.
$$

which is graphically presented in Figure 2C.

Inspecting Figure 2B and $\mathrm{C}$ leads to an interesting observation. Contrary to conventional thinking, tightening the judgment limit may result in a Pareto superior outcome. The upshot is that a tightened asset limit may drastically increase the settlement rate and that the efficiency gain from avoiding the court may outweigh the adversary effect of reduced recovery on the part of the plaintiff. ${ }^{10}$

A related issue with a significant implication for care taking is how much of the social loss from the accident is borne by the injurer. It turns out that, in our general litigation model, the liability the injurer bears may either fall short of or exceed the social loss from the accident. The social loss given by $L^{*}(B, p)=E W+\left[1-F\left(w^{*}\right)\right](c+d)$ can be less than the liability $L(B, p)$ both because of the judgment-proofness and because of the fact that the defendant is only liable with probability $p<1$; the liability might be greater than the social loss (i.e.

10 That a defendant is better off with a reduced liability limit is obvious. 
$\left.L^{*}<L\right)$, because of the extra legal cost $d$ incurred during a judicial process. ${ }^{11}$ Let $T_{1}=\left\{(B, p, c, d): L^{*}>L\right\}$ and $T_{2}=\left\{(B, p, c, d): L^{*}<L\right\}$. Unless otherwise mentioned, we will focus on the set $T_{1}$ as most plausible.

The following lemma will be useful for analysis in the remaining sections and is reported without proof.

Lemma 2: Writing in unsuppressed forms, $L(B, p, c, d)$ and $U(B, p, c, d)$,

(i) the defendant's expected liability $L(B, p, c, d)$ is non-decreasing in $B, p, d$ and non-increasing in $c$.

(ii) the plaintiff's expected recovery $U(B, p, c, d)$ is non-decreasing in $d$ and $p$ (if $\left.\varepsilon_{h} \geq 1\right)$ and non-increasing in $c$.

\section{Liability Rules and the Incentive for Care}

In this section, we study the incentives for care by utilizing the characterization of the litigation process established in the previous section. In so doing, we first examine the strict liability, a prevailing liability rule; and in the next subsection, strict liability will be compared with the negligence rule.

\subsection{Strict Liability}

In our stylized model of strict liability, a court decision does not depend on the level of care, once damage is verified. Thus, the only critical variable that affects the level of care is the (expected) amount of liability that the defendant bears. Let $L$ denote expected liability. Then, the potential injurer will, under the strict liability, choose $e_{1}$ and $e_{2}$ to

[S] Minimize $C^{S}\left(e_{1}, e_{2} ; L\right) \equiv q\left(e_{1}, e_{2}\right) L+\psi\left(e_{1}, e_{2}\right)$.

Assume:

[A3]: $q \in[0,1] ; q_{i}<0$ for $i=1,2 ; q$ is convex with $q_{12}=0$.

[A4]: $\psi_{i}>0$ for $i=1,2 ; \psi$ is convex with $\psi_{12} \leq \psi_{i i}$ for $i=1,2$.

[A5]: [S] has an interior solution for all $L>0$.

11 To see that this might happen, consider a case where $B=\bar{W}, p=1, c=0$ and $d>0$. Then

$$
\begin{aligned}
& L^{*}=\int_{w^{*}}^{\bar{w}}(w+d) d F(w)+\int_{0}^{w^{*}} w d F(w) \\
& <\int_{w^{*}}^{\bar{w}}(w+d) d F(w)+\int_{0}^{w^{*}} w^{*} d F(w) \\
& =L .
\end{aligned}
$$


[A3] implies that both efforts are conducive to reducing the chance of accident but with diminishing efficiency. [A4] is a usual assumption made for disutility associated with productive inputs. Both assumptions combined are sufficient foe the convexity of the cost function $C^{s}$, and also for the existence of the unique interior solution along with [A5]. Extra conditions in [A3] and [A4] are assumed to simplify the exposition.

Under [A3]-[A5], the following first order conditions are necessary and sufficient for $[S]$ :

$$
\text { (FOCS) } q_{1} L+\psi_{1}=0 ; \quad q_{2} L+\psi_{2}=0
$$

Let $B_{i}\left(e_{j} ; L\right)$ define the optimal level of effort of type $i$ when the liability is $L$ and effort of type $j \neq i$ is taken at $e_{j}$. By looking at the first order conditions, it is clear that $B_{i}\left(e_{j} ; L\right)$ is increasing in $L$ for $i, j=1,2$. Assume in addition: ${ }^{12}$

$$
\text { [A6]: For any } L>0, q_{1} C_{22}^{s}-q_{2} C_{12}^{s}<0 ; \quad q_{2} C_{11}^{s}-q_{1} C_{21}^{s}<0 .
$$

Then, the optimal effort choice defined as $\left(e_{1}^{s}(L), e_{2}^{s}(L)\right)$ is increasing in $L$. The following proposition is now immediate.

Proposition 3: (i) If (B, $p, c, d) \in T_{1}$ and [A1]-[A5]. then at least one type of care is underinvested under strict liability; with an additional regularity condition, [A6], both types of effort are underinvested; i.e. $\left(e_{1}^{s}, e_{2}^{s}\right)<\left(e_{1}^{s}\left(L^{*}\right), e_{2}^{s}\left(L^{*}\right)\right)$

(ii) With [A1]-[A6], $\left(e_{1}^{s}, e_{2}^{s}\right)$ are non-decreasing in $\left(B, p_{v}, d\right)$ and non-increasing in $c$.

The first statement is due to the fact that the expected amount of liability the injurer bears is less than the expected social loss from the accident. In this sense, the result is a two-dimensional generalization of Shavell (1986). The second statement has comparative static results with some potential policy implications. To understand the comprehensive welfare implications of changing parameters, however, we also need to look at the change in the settlement rate. ${ }^{13}$ Thus, by recalling Proposition 1-(ii). we have the following results (which are summarized in Figure 3):

(i) Relaxing judgment-proofness (i.e. an increase in $B$ ) increases the level of care but may drastically reduce the settlement rate.

(ii) Loosening a liability requirement (i.e. an increase in $p_{v}$ ) increase the level of care but may reduce the settlement rate.

12 This is sufficient for the convexity of $C^{s}$ but not vice versa.

13 Recall that the social loss $L^{*}$ is a sum of the expected damage $E W$ and the expected court costs which depend on settlement rate. 


\begin{tabular}{|c|c|c|c|c|}
\hline & $\Delta \mathrm{B}$ & $\Delta \mathrm{p}$ & $\Delta \mathrm{c}$ & $\Delta \mathrm{d}$ \\
\hline $\begin{array}{c}\text { Incentives } \\
\text { for care }\end{array}$ & + & + & - & + \\
\hline $\begin{array}{c}\text { Settlement } \\
\text { rate }\end{array}$ & - & - & + & + \\
\hline
\end{tabular}

Figure 3: Effects of Changes in $B, p, c$ and $d$.

(iii) A decrease in the plaintiff's litigation costs (i.e. a decrease in $c$ ) increase the level of care but may reduce the settlement rate.

(iv) An increase in the defendant's litigation costs (i.e. a decrease in $c$ ) increases the level of care, and may simultaneously increase the settlement rate.

The upshot is that each parameter change has a different welfare implication because of its differing impact on settlement and liability. When $L<L^{*}$, an increase in $d$ turns out to be most effective, both increasing the incentive for care and simultaneously encouraging out-of-court settlement. This observation leads to a revelation of yet another aspect of an often discussed policy alternative; the use of the damage multiplier in conjunction of decoupling. ${ }^{14} \mathrm{~A}$ traditional argument for decoupling was that an optimal enforcement mechanism [in the sense of Gary Becker (1968)] with the right mix of detection rate and amount of penalty can be implemented through decoupling, since it makes it possible for the detection rate to be reduced while increasing the defendant's payment through the use of damage multiplier (Polinsky 1986). Here, we identify another beneficial role of decoupling - a role quite similar to that of an increase in $d$. In our model, decoupling can be used to reduce the expected legal costs at the same time as an optimal adjustment is made, by the damage multiplier to liability. To examine these issues, let $m_{d}$ and $m_{p}$ denote the multiplier applied to the defendant's payment and the plaintiff's award, respectively. Under the pure damage multiplier approach, $m_{d}=m_{p}\left(\begin{array}{l}> \\ =1\end{array}\right)$; while under the decoupling approach $m_{d} \neq m_{p}$ in general. The following proposition establishes the benefit of decoupling.

14 The damage multiplier approach refers to an arrangement where the court imposes to the defendant (and awards to the plaintiff) a payment, which can be either greater or less than the compensatory damage. Under coupling, the plaintiff's judgement award is allowed to differ from what the defendant pays. One example of decoupling would be that the court orders the defendant to pay treble damage and yet only awards compensatory damage to the plaintiff. 
Proposition 4: Let $B>\hat{B}$ and [A1]-[A6] hold.

(i) A pure damage multiplier approach, by setting $m_{d}=\left(m_{p}\right)>1$ can increase the level of both types of care but only at the expense of increasing the legal costs.

(ii) Under the decoupling approach, the performance of the damage multiplier can be enhanced by setting $m_{p}<\min \left\{m_{d}, 1\right\}$ which reduces the expected legal costs by encouraging settlement.

Proof: That setting $m_{d}>1$ can raise expected liability and improve the incentives for care under both approaches is obvious. To examine the impact on the expected legal costs of each approach, we need to study the settlement rates under two approaches. The settlement rates, with $B>\hat{B}$, are determined by the following first order conditions. Under the pure damage multiplier approach, $w_{D M}^{*}$ is determined by

$$
h\left(w_{D M}^{*}\right)=\frac{c+d}{p m_{d}}
$$

which is less than $\frac{c+d}{p}$ when $m_{d}>1$. This implies that $w_{D M}^{*}<w^{*}$ when $m_{d}>1$; i.e. expected legal costs are increased under the pure damage multiplier. On the other hand, under the decoupling approach with $m_{p}<\min \left\{m_{d}, 1\right\}$, the settlement rate $w_{D C}^{*}$ is greater than $w^{*}$ since it is determined by

$$
h\left(w_{D C}^{*}\right)=\frac{c+d+p\left(m_{d}-m_{p}\right) w_{D C}^{*}}{p m_{p}}
$$

which is greater than $\frac{c+d}{p}$. This implies that $w_{D C}^{*}>w^{*}$. Therefore, expected legal costs are decreased under decoupling.

According to the proposition, it helps to decouple the amount of penalty from that of award in such a way that the defendant pays more than the plaintiff receives. This payoff structure provides an extra penalty (resp. reward) to the defendant for going to (resp. avoiding) the court, since now the defendant has to pay more on losing the trail than she needed to, had she settled. The welfare implication of this is that there will be more settlement, and fewer legal costs incurred than would be true without decoupling. The good news is that this can be done all at the same time as a desirable adjustment is made to the level of liability.

\subsection{Comparison with Negligence Rule}

This subsection will examine the performance of the negligence rule, and compare it with the performance of the strict liability. Recall that in our representation of 
the negligence rule, the legal standard applied is uncertain, being realized by the jury's interpretation of "due care." Suppressing our liability function $L(B, p, c$, $d)$ to reveal only the winning probability in argument, $L\left(p_{N}\left(e_{1}\right)\right)=L\left(p_{v}\left(1-G\left(e_{1}\right)\right)\right)$ as introduced before. Notice that the uncertain standard applies only to $e_{1}$, the observed care. With this modification of the liability function, the defendant's problem under the negligence rule can be expressed as:

$$
[\mathrm{N}] \min C^{N}\left(e_{1}, e_{2}\right) \equiv q\left(e_{1}, e_{2}\right) L\left(p_{v}\left(1-G\left(e_{1}\right)\right)\right)+\psi\left(e_{1}, e_{2}\right) .
$$

Notice here that comparing to strict liability, the amount of liability is itself a decreasing function of the observed effort $e_{1}$, revealing an incentive sharpening caused by the negligence rule. For analytical convenience, we assume:

[A7]: $C^{N}$ is convex.

$$
\text { [A8]: } \psi_{12}>0
$$

The immediate implication of [A7] is that the program [N] has a unique solution. ${ }^{15}$ As for [A8], the efforts are said to be substitutes when the condition holds. The condition is suitable to describe a situation where the two types of effort are subject to a common budget or time constraint so that increasing one type of effort increases the marginal cost of increasing the other type of effort. In the example of nuclear power plants, this corresponds to a situation where purchasing an additional unit of safety facility makes it harder to increase the employment of maintenance workers when both actions are funded by a common, rigid budget constraint. On the contrary, when $\psi_{12}<0$, which we label as [A8'], the two types of effort are said to be complements. The latter assumption is useful in modeling a positive reinforcement between the types of care.

Now, with [A7], the Kuhn-Tucker condition (without comparative slackness) is given by

$$
\text { (FOCN) } q_{1} L+q L_{p} p_{N}^{\prime}+\psi_{1} \leq 0 ; \quad q_{2} L\left(p_{N}\right)+\psi_{2} \leq 0
$$

Let $B_{i}^{N}\left(e_{j}\right)$ denote the best response, which is analogously defined as $B_{i}$. It follows from (FOCN) that $B_{1}^{N}\left(e_{2}\right)>B_{1}\left(e_{2} ; L\left(p_{N}\left(e_{1}\right)\right)\right)$ and $B_{2}^{N}\left(e_{1}\right)=B_{2}\left(e_{1} ; L\left(p_{N}\left(e_{1}\right)\right)\right)<B_{2}\left(e_{1} ; L\left(p_{s}\right)\right)$. The first result is due to the extra incentive added on the observed care, $e_{1}$. The second result follows since the way the incentive is provided for the unobserved care $e_{2}$ is the same as before (i.e. the strict liability) but now the injurer bears less liability because of the extra protection

15 Remember that $G$ has a compact support. 
(i.e. $p_{N}=p_{v}(1-G)<p_{v}=p_{s}$ for all $\left.e_{1}\right)$. Now we are in a position to present one of the main propositions of this essay.

Proposition 5: Assume [A1]-[A8] and let $\left(e_{1}^{N}, e_{2}^{N}\right)$ be the solution to [N]. Then, (i) $e_{2}^{N}<e_{2}^{S}$; i.e. the level of unobserved effort is smaller under the negligence rule than under strict liability.

(ii) Once an accident occurs, under the negligence rule (1) a settlement is more likely; (2) the defendant bears smaller expected liability; (3) the plaintiff's expected recovery is smaller (with $\varepsilon \geq 1$ ), than under the strict liability.

Proof: The second statement is obvious from $p_{N}<p_{S}$ and proposition 1 and lemma 2. To demonstrate the first statement, Let $\tilde{L}=L\left(p_{N}\left(e_{1}\right)\right)$. We know from the second statement, $\tilde{L}=L\left(p_{s}\right)$. Thus, [A6] implies $e_{2}^{s}(\tilde{L})<e_{2}^{s}$. Since $e_{1}^{N}=B_{1}^{N}\left(e_{2}^{N}\right)>B_{1}\left(e_{2}(\tilde{L}) ; \tilde{L}\right)=e_{2}^{s}(\tilde{L})$. [A8] implies that

$$
e_{2}^{N}=B_{2}\left(e_{1}^{N} ; \tilde{L}\right)<B_{2}\left(e_{1}^{s}(\tilde{L}) ; \tilde{L}\right)=e_{1}^{s}(\tilde{L})<e_{2}^{s} .
$$

The underinvestment in unobserved care is due to two effects: (1) the potential injurer, being further protected by the negligence rule, faces a smaller expected liability relative to strict liability; (2) with the efforts being substitutes, a sharpened incentive on observed effort under the negligence rule diverts the attention of the potential injurer away from unobserved effort. The second effect was first introduced in a principal-agent framework by Holmstrom and Milgrom (1991). Without the assumption [A8], the second effect works in the opposite direction. However, if the first effect is sufficiently strong, the underinvestment result will still hold.

It is not clear in general how the observed effort $e_{1}^{N}$ will be determined. Two effects are competing: on the one hand, the injurer receives a weaker threat from the liability level itself; on the other hand, she receives a more sharpened incentive for the effort, $e_{1}$. The net effect is ambiguous. Suppose $e_{1}^{N}<e_{1}^{S}$. Then, accidents will occur more frequently under the negligence rule than under strict liability. However, a strong possibility is that $e_{1}^{N} \geq e_{1}^{S}$. This will occur, for example, if the negligence standard is higher than $e_{1}^{S}$ with probability one: i.e. $G=0$ for $e_{1}<e_{1}^{S}$.

In general, welfare comparison of these liability rule is complicated. There is a certain benefit to be gained from the negligence rule in the form of higher settlement rate. However, if the unobserved effort is sufficiently important and the settlement rates are not that different, then the perverse effect of the negligence rule on the unobserved effort may turn out to be sufficiently damaging so that the strict liability should be favored over the negligence rule. Such a possibility will be explored when we introduce the certain negligence rule. 
Under the certain negligence rule, the standard of "due care" is predetermined at $e_{1}^{*}$. Therefore, the plaintiff's winning probability is now a step function:

$$
p_{C N}\left(e_{1}\right)=\left\{\begin{array}{c}
p_{v}, \text { if } e_{1}<\underline{e_{1}^{*}} \\
0, \text { if } e_{1} \geq \underline{e_{1}^{*}}
\end{array}\right.
$$

Therefore, if the injurer complies with the standard by picking $e_{1}^{*}$, he is fully immunized from any further liability. That is, $L\left(p_{C N}\left(e_{1}^{*}\right)\right)=0$. Therefore, when the injurer complies with the standard, she will always pick the zero level of unobserved effort. Knowing this, the court will optimally set the standard at

$$
\underline{e_{1}^{*}} \in \operatorname{argmin}_{e 1} q\left(e_{1}, 0\right) E W+\psi\left(e_{1}, 0\right) .
$$

If either $B$ or $p$ is sufficiently small, the injurer will find it more profitable not to comply with the optimal standard, since even without appealing to the negligence standard the amount of liability is ignorable with small $B$ or $p$. In this case the effort choice of the injurer will be the same as under the strict liability. To prevent such a case, we assume

$$
\text { [A9]: } \min C^{S}\left(e_{1}, e_{2}\right)>\psi\left(\underline{e_{1}^{*}}, 0\right) .
$$

Thus, under this condition, an uncertain negligence standard may be superior to the certain standard. To summarize the analysis,

Proposition 6: If [A1]-[A9] hold, and $\underline{e_{1}} \geq \underline{e_{1}^{-}}$and $\underline{e_{1}^{+}} \geq \underline{e_{1}^{*}}$,

(i) $e_{1}^{C N}=\underline{e_{1}^{*}}>e_{1}^{N}>e_{1}^{S}$ and

(ii) $e_{2}^{C N}=0<e_{2}^{N}<e_{2}^{S}$.

Proof: The first result follows since for all $e_{1} \geq e_{1}^{*}$ and $e_{2}>0$

$$
q_{1}\left(e_{1}, e_{2}\right) L+\psi_{1}\left(e_{1}, e_{2}\right)>q_{1}\left(\underline{e_{1}^{*}}, 0\right) E W+\psi_{1}\left(\underline{e_{1}^{*}}, 0\right) .
$$

The intuition of the proposition is clear: given that the uncertain negligence standard never exceeds $e_{1}^{*}$ (which is itself very plausible), certainty in legal standards induces a higher level of observed effort but a lower level (actually zero) of unobserved effort than does uncertain legal standard. Therefore, if the unobserved effort is sufficiently important, the uncertainty in legal standards will likely be socially beneficial. An important feature of uncertain legal standards in that the negligence rule is combined with some element of strict liability: even if the injurer takes a significantly high level of observed care, she still faces some chance of being held liable. This features of mixing a strict liability element with 
the negligence rule, I suspect, will be more beneficial as dimensions of the effort increases and the number of observed effort types decreases. One clear policy implication of this result is that the current approach of delegating to the jury the burden of interpreting the standard of "due care" may not be entirely misplaced in a world of multi-dimensional care and limited observability.

Finally, we establish some welfare comparison of the liability rules. To simplify the exposition. Let's assume

$$
\begin{aligned}
& {\left[\mathrm{A}^{\prime}\right]: q\left(e_{1}, e_{2}\right)=k x\left(e_{1}\right)+(1-k) x\left(e_{2}\right), \text { where } k \in[0,1] \text { and } x^{\prime}<0, x^{\prime \prime}>0,} \\
& x(0)=1, x(\infty)=0 ; x^{\prime}(0)=-\infty, x^{\prime}(\infty)=0 .
\end{aligned}
$$

For the next analysis, [A3] and [A5] are replaced by [A3']. The assumption [A3'] simplifies the analysis in the following two senses. The accident rate is additively separable so that any interaction between the two types of effort is relegated to the disutility function $\psi$. Secondly, the parameter $k$ simplify measures the importance of the observed care.

Proposition 7: Let [A3'] replace [A3] and [A5] and keep all the other assumptions, then

(i) strict liability is socially better than the certain negligence rule if $k$ is sufficiently small;

(ii) strict liability is socially worse than the certain negligence rule if $\mathrm{k}$ is sufficiently large.

Proof: Suppose $k=0$. Then, $e_{1}^{s}=e_{1}^{C N}=0<e_{1}^{*}$; but $e_{2}^{C N}=0<e_{2}^{S}<e_{2}^{*}$. Therefore, $q\left(e_{1}^{S}, e_{2}^{S}\right) E W+\psi\left(e_{1}^{S}, e_{2}^{S}\right)<q\left(e_{1}^{C N}, e_{2}^{C N}\right) E W+\psi\left(e_{1}^{S}, e_{2}^{S}\right)$, demonstrating the superiority of strict liability. Since all the variables move smoothly as $k$ increases, the relationship holds in the neighborhood greater than $k=0$.

Now to show (ii), let $k=1$. Then, the model is equivalent to single activity model with full observability. In this case, we know that $e_{1}^{S}<e_{1}^{C N}=0=e_{1}^{*}$; and $e_{2}^{S}<e_{2}^{C N}=e_{2}^{*}=0$. Thus, the certain negligence rule is socially better. As before, the result holds in the neighborhood less than $k=1$.

Contrary to what is believed in the traditional one-activity model, according to the analysis above, strict liability may deserve some merit not only on insurance grounds but also on deterrent-effect grounds when care is multi-dimensional. Also, the result seems to suggest that current debates and reform movements over liability rules are somewhat misguided in that they suggest a universal shift toward or against the negligence rule. Each liability case is different in terms of the dimensionality and observability of relevant care, and therefore warrants a different approach. Although a continued effort in universal reform is important, 
the analysis of this paper suggests that the choice of a liability rule may be a case specific matter that needs to be determined by carefully weighing the cost and benefit of liability rules in each case.

\section{Safety Regulation in the Presence of Litigation}

In this section, the performance of safety regulations is examined. In many situations, especially in product and safety liability contexts, the actions that could engender the potential liability litigations are of great public concern as well and are usually subject to regulation. Therefore, it is important to understand what the role of regulation would be with and without the presence of future litigation possibilities, and if a litigation threat exists, how a regulatory standard should be set to best supplement the incentive role of the court.

We represent regulation as imposing a minimum standard. Suppose for a moment that there is no litigation and that regulation is the sole source of incentives for care. If a regulatory agency monitors both types of effort, $e_{1}$ and $e_{2}$, then the first best level of care $\left(e_{1}^{*}, e_{2}^{*}\right)$ can be enforced by using some form of sanction similar to a forcing contract. However, more realistically, the agency will likely monitor some types of care, but not others for various reasons. ${ }^{16}$ Suppose the agency monitors one type of effort $\left(e_{1}\right)$ but not the other $\left(e_{2}\right)$. Then, the best that regulation can do is to mimic the performance under the litigation with a certain negligence rule. In other words, an agent under regulation would be completely careless in exerting unmonitored care and to offset this an optimal regulatory standard on the monitored care would be set at an otherwise excessively high level $e_{1}^{*} \cdot{ }^{17}$ According to the analysis in previous section, litigation under strict liability $\overline{\text { or }}$ a negligence rule with uncertain standards has a potential to outperform such regulation. Therefore, in what follows, we will assume the existence of liability litigation; and the focus will be placed on how regulation can be designed to best supplement the performance of the court. We assume that the court adopts strict liability. The case with the negligence rule will be briefly considered later.

16 A regulatory agency may find some type of activity too costly to monitor, and others politically too distasteful to monitor; a mandatory drug testing of safety related workers is one such example.

17 In this model, this kind of regulation is still better than no regulation; since the latter induces zero effort on both types of activity. The result hinges on the feature of the model that any positive level of effort is costly to the agent. No regulation may be better than the partial regulation if unregulated agent has some private incentive to exert effort, as is the case in Holmstrom and Milgrom (1991). 
It turns out that the performance of regulation depends on whether the two efforts types are substitutes or complements; i.e. [A8] or [A8']. The following proposition establishes ineffectiveness of the regulation when the efforts are substitutes.

Proposition 8: Under [A1]-[A8], regulation which improves the incentive of one type of effort aggravates the incentive of the other type.

The proposition can be best explained by using Figure 4A.

The curves $B_{1}^{S}$ and $B_{2}^{S}$ describe the best response functions which solve the first order conditions [(FOCS) above] under strict liability. The curves $B_{1}^{*}$ and $B_{2}^{*}$, called social best response functions, depict the similar best response functions with liability $L$ replaced by the social loss $L^{*}$ form the accident. In the picture, $L<L^{*}$. The best response curves are negatively sloped with an absolute value of slope less than one, due to [A.4] and [A.8]. In this case the only way the regulatory agency can improve the incentive for $e_{1}$ is to set a regulatory standard at $e_{1}^{R}$ greater than the unregulated choice $e_{1}^{S}$. This regulatory measure will obviously aggravate the incentive for $e_{2}$; since the agent, under the regulation, will pick $e_{2}^{S^{\prime}}$. The intuition for this result is similar to the effect of introducing the negligence rule; and the same as that of Holmstrom and Milgrom (1991): regulation which emphasizes the monitored action diverts the agent's attention away from - and therefore worsens the incentive for - the unmonitored action. Regulation in this situation, therefore, will be welfare reducing, unless the monitored action is sufficiently more important than the unmonitored one in preventing an accident.

Regulation can be effective if the effort types are complementary; i.e. [A8'].

When the two effort types are complementary, increasing the level of one type of effort makes it less costly to increase the other type. Graphically, this feature is represented as positively sloping best response function (with a slope less than one due to [A4]). The positive reinforcement between the efforts makes regulation effective. The regulation which enforces the level of the monitored effort $\left(e_{1}^{R}\right)$ to be greater than its unregulated level $\left(e_{1}^{S}\right)$ also increases the level of unmonitored effort $\left(e_{1}^{S^{\prime}}\right)$ above its unregulated level $\left(e_{2}^{S}\right)$. According to Figure 4B, the optimal level of the regulatory standard must be greater than $\tilde{e}_{1}$, where $\tilde{e}_{1}=B_{1}^{*}\left(B_{2}^{s}\left(\tilde{e}_{1}\right)\right)$. (See Figure 4B).

Proposition 9: Under [A1]-[A7] and [A8'] (complementarity), regulation which improves an incentive for one type of effort also improves the incentive for the other type, and that the optimal regulatory standard $e_{1}^{R}$ is greater than $\tilde{e}_{1}$.

Proof: It suffices to show the second point. For all $e_{2} \leq \tilde{e}_{2}$, 

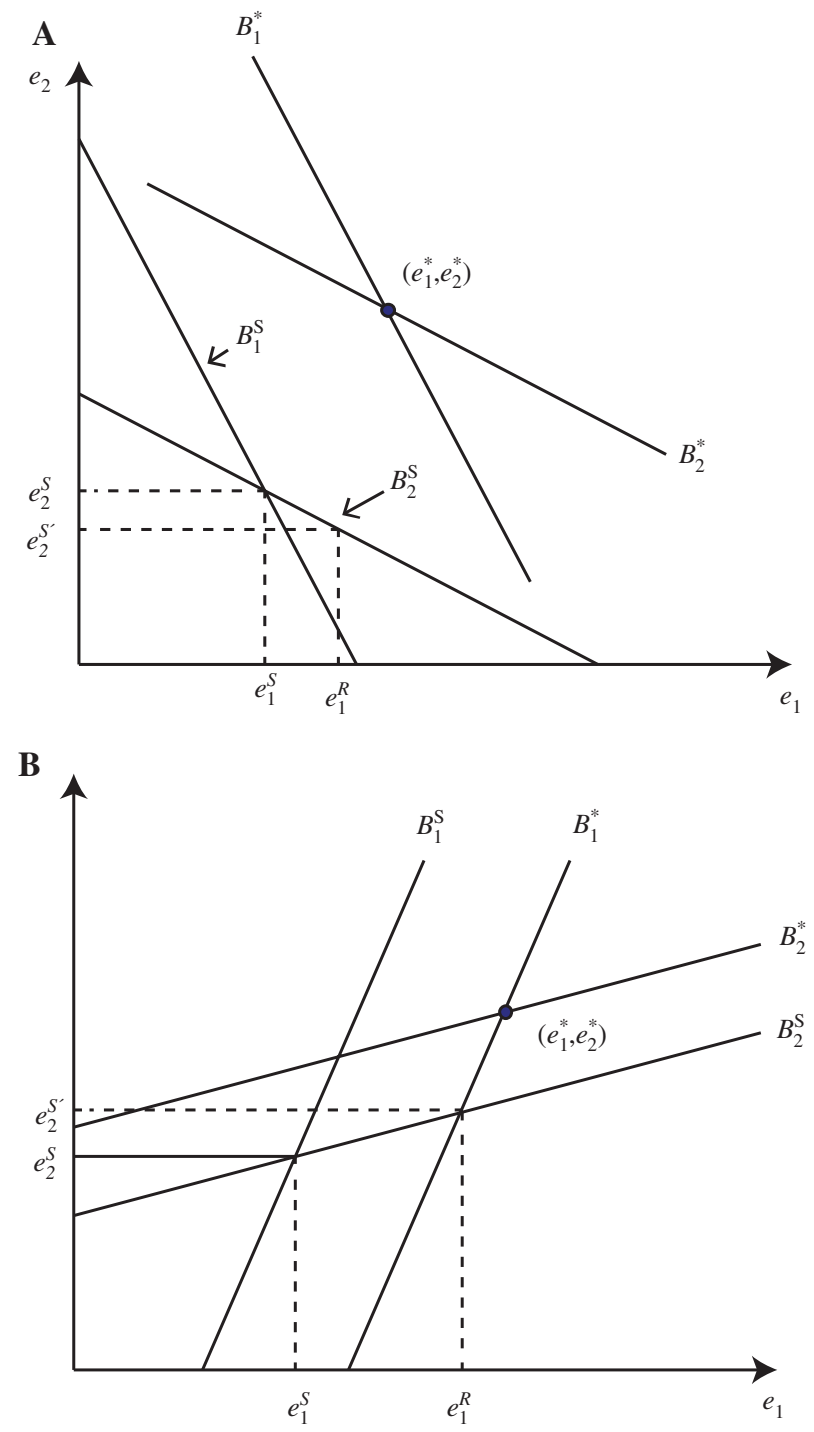

Figure 4: (A) Equilibrium when Efforts are Substitutes. (B) Equilibrium when Efforts are Complements.

$$
\frac{d}{d e_{1}} C^{*}\left(e_{1}, B_{2}^{s}\left(e_{1}\right)\right)=C_{1}^{*} B_{2}^{S^{\prime}}\left(e_{1}\right)+C_{2}^{*}<0,
$$

where $C_{2}^{*} \leq 0$ by the definition of $\tilde{e}_{1} ; C_{1}^{*}<0$ since $B_{2}^{S}\left(e_{1}\right)<B_{2}^{*}\left(e_{1}\right)$; and finally $B_{2}^{S^{\prime}}\left(e_{1}\right)>0$ since $\psi_{12}<0$. 
The above analysis is based on the court's adopting strict liability. If the negligence rule is adopted, then a crucial question is whether or not a regulatory standard will affect the negligence standard interpreted by the jury. If it does not, the problem is qualitatively the same as before.

Now, on the contrary, suppose as an extreme example the jury interprets "due care" to be fulfilled whenever regulatory standards are met by the injurer. That is, $e_{1}^{+}<e_{1}^{R}$. Then, we are back to the regime of the certain negligence standard: even though the jury's interpretation is uncertain, it is uncertain only in the irrelevant region. In this case, the injurer will be completely careless on unmonitored effort because regulation essentially eliminates the threat of liability and thereby its useful incentive feature, once the regulatory standard is met. Furthermore, the court is completely redundant; actually, there is no litigation since fulfilling regulatory standards completely immunizes the potential injurer. Therefore, when the court adopts the negligence rule, regulation can undermine, instead of supplementing, the effectiveness of the court, by neutralizing the potentially beneficial uncertainty feature of the negligence standard.

\section{Concluding Remarks}

The paper has examined the performance of alternative liability rules and regulation, when an injurer's care is multi-dimensional. The results and policy implications of the analysis that have been reported throughout the paper suggest that a much different understanding could be gained about the incentive role of liability and regulation by considering the two-dimensional effort problem.

The intuition as well as the general analytic framework developed in this paper can be extended to accommodate other interesting problems. The following are a few examples:

(i) victim's care, contributory negligence: The two-effort model can be easily modified to address the problem. Relabeling $e_{1}$ and $e_{2}$ as effort taken by an injurer and a victim, respectively, we can easily establish: (1) under strict liability both parties will take less than socially optimal level of care, since each party bears only a fraction of the social loss of accident; (2) a shift to a negligence rule could improve the incentives of both parties, as the victim bears more loss and the injurer faces a sharper incentive; (3) the use of the contributory negligence rule can further improve the victim's incentive both under strict liability and negligence; (4) the use of the "certain" negligence rule restores the first best outcome, in which case the contributory negligence will have no further value. 
(ii) liability insurance: Under strict liability, liability insurance has neither private nor social value unless the insurer observes both types of effort. On the other hand, under the negligence rule, liability insurance may be privately valuable if the insurer has an ability to more credibly present to the court (than the defendant) the evidence that the defendant is non-negligent. If this increased credibility in court presentation implies an increase in the marginal gain from the observed effort, the social welfare will likely be diminished, since the potentially perverse effect of the negligence rule gets amplified.

(iii) precedent and English Fee system: Che and Yi (1993) recognized that the precedent and English fee system have a common feature that each party is more sensitive to the change in the likelihood of winning the trial; i.e. winning matters more when it has an external effect. In the framework of this paper, this simplify means that the defendant's liability is a steeper function of the plaintiff's winning probability. This feature will imply that the incentivesharpening caused by a shift to the negligence rule is much more significant than without such a feature. We can expect that the potentially perverse effect of the negligence rule on unobserved effort will be even more severe with such a feature.

Acknowledgments: This paper owes a great deal of inspiration from Paul Milgrom. It also benefits from conversations with Mitchell Polinsky and Jong Goo Yi, which allowed me to take much richer perspectives than I had initially set out. Editorial comments from Beverly McChesney and Ed Steinmueller were very helpful. Financial support from Center for Economic Policy Research and John Olin Foundation is gratefully acknowledged.

\section{Appendix}

Proof of proposition 1:

The proof of (i) follows several steps: First let $w(B, p) \in \operatorname{argmin} L(w ; B, p)$. Then,

(1) $w(B, p)=B$ if $w(B, p) \geq B$; while $w(B, p)=w^{*}$ if $w(B, p)<B$ :

The first statement is obvious by inspecting $[D]$. For the second statement, from $[D]$ we know

$$
w(B, p) \in \arg \min _{w \in[c / p, B]} \bar{L}(w ; B, p)
$$

But since $w \geq B$, 


$$
L(w(B, p) ; B, p)<L(B ; B, p) \leq L(w ; B, p),
$$

which implies

$$
w(B, p) \in \arg \min _{w \in[c / p, \bar{W}]} \bar{L}(w ; B, p)
$$

Therefore, $w(B, p)=w^{*}$.

(2) $L(B, p)=\max \{\min \{B p-c, \bar{L}(w ; B, p)\}, 0\}$ :

The result follows since $w(B, p)$ is either $B$ or $w^{*}$ and from that $w^{*} \geq B$ implies $B p-c<\bar{L}\left(w^{*} ; B, p\right)$.

(3) (i):

The result follows since $B p-c<\bar{L}\left(w^{*} ; B, p\right)$ for $B \leq w^{*} ; B p-c>\bar{L}\left(w^{*} ; B, p\right)$ for $B \geq w^{*}$ and finally from the fact that

$$
\frac{d(B p-c)}{d B}>\bar{L}_{B}\left(w^{*} ; B, P\right) .
$$

Finally, (ii) follows by inspecting the function $L(B, p)$ in (2).

\section{References}

Bebchuk, L. A. 1984. "Litigation and Settlement under Imperfect Information." Rand Journal of Economics 15: 404-415.

Becker, G. 1968. “Crime and Punishment: An Economic Approach.” Journal of Political Economy 76: 169-217.

Calfee, J. E., and R. Craswell. 1984. "Some Effects Uncertainty on Compliance with Legal Standards." Virginia Law and Review 70 (5): 965-1003.

Che, Y. K., and J. G. Yi. 1990. "Litigations with Multiple Plaintiffs." Stanford University, Stanford, CA: mimeo.

Che, Y. K., and J. G. Yi. 1993. "The Role of Precedents in Repeated Litigation.” Journal of Law, Economics and Organization 9: 399-424.

Holmstrom B., and P. Milgrom. 1991. "Multi-Task Principal-Agent Analyses: Incentive Contracts, Ownership, and Job Design." Journal of Law, Economics and Organization 7: 24-52.

P'ng, I. 1987. “Litigation Liability, and Incentives for Care." Journal of Public Economics 34: 61-85.

Polinsky, A. M. 1986. “Detrebling Versus Decoupling Antitrust Damages: Lessons from the Theory of Enforcement.” The Georgetown Law Journal 74 (4): 1231-1236.

Polinsky, A. M., and D. L. Rubinfeld. 1988. "The Welfare Implications of Costly Litigation for the Level of Liability." The Journal of Legal Studies 17 (1): 151-164.

Priest, G. L. 1987a. “Modern Tort Law and Its Reform.” Valparaiso Law Review 22 (1): 1-38.

Priest, G. L. 1987b. "Modern Products Liability Law and Its Effect on the Accident Rate." Yale Law School Working Paper No 66. 
Priest, G. L. 1991. “The Modern Expansion of Tort Liability: Its Source, Its Effect, and Its Reform.” Journal of Economic Perspective 5 (3): 31-50.

Shavell, S. 1984. "A Model of the Optimal Use of Liability and Safety Regulation." Rand Journal of Economics 15 (2): 271-280.

Shavell, S. 1986. "The Judgement Proof Problem." International Review of Law and Economics 6: 45-58. 